\title{
A CORPUS-BASED ANALYSIS OF HEDGES AND BOOSTERS IN ENGLISH ACADEMIC ARTICLES
}

\author{
Masahiro Takimoto \\ Aoyama Gakuin University \\ ra57482@rd5.so-net.ne.jp
}

Article received: 19 January 2014

Final proof received: 27 June 2015

\begin{abstract}
The present study examined research articles from eight academic disciplines to measure the frequencies and functions of hedges and boosters. The quantitative results showed that hedges exceeded boosters, with philosophy articles showing a significant use of hedges and boosters. The natural science papers were underrepresented in the number of hedges and boosters. Moreover, the results indicated that the choices the writers make seem to be constrained by the discourse norms and rhetorical styles of each discipline and reflect the nature of different disciplinary characteristics. The humanities and social sciences are basically more interpretative and less abstract, a style that requires more hedges and boosters and opts for subjectivity, whereas natural sciences are typically more fact-oriented and more impersonal, which is accompanied by fewer hedges and boosters and opts for objectivity. This was confirmed by a further analysis that showed that the relative incidence of hedges of the possibility/probability category in adjectives and adverbs was the highest in humanities and the lowest in natural sciences. Moreover, the relative incidence of hedges of the tentative cognition category in nouns and verbs was the highest in humanities and social sciences and the lowest in natural sciences.
\end{abstract}

Keywords: hedge, booster, modality, writing

The concept of the hedge was popularized as a linguistic term by Lakoff (1972), who defined it as "words whose job it is to make things fuzzier or less fuzzy" (Lakoff, 1972, p. 195). Lakoff's basic concept is that hedges modify words or phrases within a proposition, making the border fuzzier or making the border less fuzzy. However, to date, the research tradition on hedges has focused more on the attenuation aspect (Fetzer, 2010; Fraser, 2010). Recently, though, because the concept of a hedge includes not only the modification of words or phrases within a proposition but also the modification of one's commitment to the propositional content, some researchers have begun to think it is necessary to distinguish between the two types of hedging. Writers express their judgments, opinions, and commitments toward the propositional content of the text and their readers through the use of hedges and boosters, modifying the truth-value of the whole proposition. While hedging devices reduce the strength or force of an expression by expressing tentativeness and possibility, boosting devices intensify or emphasize the force by expressing conviction and asserting a proposition with confidence (Holmes, 1995; Hyland, 1998).

The original notion of hedges and boosters was further developed to accommodate the approaches in which hedges and boosters are used to realize an interactional/ communicative strategy and in which hedges are also used to hide the writer's epistemic attitude (e.g., Your shoes are a little bit dirty) (Markkanen \& Schröder, 1997). Furthermore, Markkanen and Schröder (1997) suggested that hedges can offer a possibility for textual manipulation in the sense that the reader is left in the dark regarding the truth value of what is being expressed and who is responsible for it. On the other hand, Hyland (1998) argued that boosters leave the reader little room for their own interpretations and are used to create interpersonal solidarity with the reader. Hyland (1998) also indicated that hedging and boosting are necessary ways for making scientific statements in social contexts, and they are not only accuracy-oriented but also writer-oriented and reader-oriented. Thus, hedges and boosters refer to the textual strategies of using linguistic means in a certain speech act for specific communicative purposes, and these pragmatic aspects of hedges and boosters are closely related to modality.

\section{Modality, hedges, and boosters}

There is a close connection among modality, hedges, and boosters. Modality is concerned with a speaker's/writer's attitude toward the truth-value or factual status of a proposition. Similarly, hedges and boosters are related to a subject's personal attitudes toward the propositional content. For example, in "It may be true," may is a hedge and in "It must be true", must is a booster, but also both expressions show epistemic modality.

Palmer (2007) considered epistemic and evidential modalities as a propositional modality that relates to the speaker's/writer's attitude toward the truth-value of the proposition. According to Palmer (2007), included under epistemic modality are three types of judgment: "One that expresses uncertainty (e.g., John may be in his office), one that indicates an inference from observable evidence (e.g., John must be in his office), and one that indicates inference from what is generally known (John 
will be in his office)" (p. 24). In other words, epistemic modality concerns the way speakers or writers communicate their doubts, certainties, and guesses. These are identified as speculative, deductive, and assumptive and overlap with hedging and boosting.

Regarding evidential modality, Chafe (1986) defined evidential modality as "any linguistic expression of attitudes toward knowledge" (p. 271), whereas Palmer (2007) defined it as reported (general knowledge and hearsay) and sensory (visual and auditory evidence). According to Chafe (1986), knowledge refers to belief, induction, hearsay, and deduction, which are based on a different source. Most of the expressions that Chafe (1986) provided as examples of the realization of these different modes are expressions that were included in hedges (Markkanen and Schröder, 1997) as well as boosters. However, Nuyts (2006) considered that Chafe's definition is too broad and that the speaker's evaluation of the possibility/probability of the state of affairs under Chafe's definition of evidential modality is related to epistemic modality (e.g., John may be unmarried ${ }^{1}$ ). As there are occasions when epistemic implications of hearsay or sensory information take place, it is difficult to draw a line between the epistemic modality and evidential modality under such occasions. In sum, the epistemic modality related to expressing speculation, deduction, and assumption largely overlaps with hedging and boosting. On the other hand, evidential modality

Table 1. Categories and examples of adjectives and adverbs

\begin{tabular}{ccccc}
\hline & Possibility/ & Indefinite & Indefinite degree & Approximation \\
& Probability & frequency & & \\
\hline Adjectives & probable & frequent & modest & approximate \\
& possible & general & moderate & rough \\
& likely & regular & reasonable & \\
Adverbs & perhaps & frequently & mainly & approximately \\
& possibly & often & primarily & roughly \\
& probably & sometimes & relatively & \\
\hline
\end{tabular}

Table 2. Categories and examples of nouns and verbs

\begin{tabular}{llll}
\hline & Non-factive claim & Tentative cognition & Tentative likelihood \\
\hline \multirow{2}{*}{ Nouns } & Claim & assumption & likelihood \\
& Prediction & hypothesis & tendency \\
& Suggestion & inference & uncertain \\
& Claim & anticipate & appear \\
& Indicate & assess & seem \\
& Predict & assume & tend \\
\hline
\end{tabular}

occurs as hedges or boosters, but the chance of evidential modality being interpreted as hedges or boosters is specially contextualized in the case of modal verbs and adverbs, and in the case of modal adjectives, the chance is conditioned by impersonal syntactic structure.

Based on the close connection with modality and the models introduced by Hyland (1998) and Varttala (2001), adjectives, adverbs, nouns, and verbs are divided into the following categories in the Tables 1 and 2:

Studies in hedges and boosters of $\mathrm{L} 1$ academic writing A number of studies in hedges have dealt with academic or scientific writing. Hedges are considered to be markers of uncertainty, and uncertainty is a fundamental characteristic of science writing. Grabe and Kaplan (1997) suggested that the motivation for expressing weak form negation with stronger pragmatic understanding involves the use of hedging or of politeness strategies. In addition, Hyland (1998) argued that in science writing, hedges play a critical role in gaining approval for writers' claims from readers by presenting statements with appropriate accuracy, caution and humility. Examples of studies in hedges include medical English written discourse (Salager-Meyer, 1994); comparison of academic science writing and popular science writing (Crismore \& Farnsworth, 1990); analysis of academic writing in the sciences, humanities and social sciences (Grabe \& Kaplan, 1997; Hyland, 1998); and analysis of modal verbs in science writing (Butler, 1990).

Salager-Meyer (1994) looked into how the communicative purpose of the different rhetorical sections of research papers (RP) and case reports (CR) in medical English written discourse influences the frequency and category distribution of hedges in each section by analyzing a corpus of 15 articles from five leading medical journals such as The British Medical Journal, Annals of Internal Medicine, The Lancet, Archives of Internal Medicine, and The New England Journal of Medicine. The frequency and percentages of hedges in the different rhetorical sections were computed, and the hedges were classified into five preestablished categories, such as shields, compounds, approximators, emotionally charged expressions, and authors' insufficiency and doubt. The results showed that the three most frequently used hedging devices are shields, approximators, and compound hedges with the discussion (RP)/comment (CR) the most heavily hedged 
and the method/case report the least-hedged.

Butler (1990) examined a corpus of 12 scientific texts, 4 from each of three subject areas, namely physics, botany and animal physiology, in a careful analysis of modal verb use. The results demonstrated that modal verbs account for approximately 10 in every 1000 words in the corpus and that the most frequent modal is may, followed by can and will with the density of modals highest in the discussion section and low in the method and result sections. Crismore and Farnsworth (1990) analyzed professional writing and popular writing on biology. Their findings indicated that hedges were used more extensively in both writings with more hedges than boosters used in the professional writing. In consideration of their findings, Crismore and Farnsworth (1990) concluded that hedging is the mark of a professional scientist. Similarly, Grabe and Kaplan (1997) examined patterns of linguistic variation across a range of expository texts consisting of 10 texts, each from five text types, such as professional natural science, popular natural science, newspaper editorials, annual business reports, and fiction narratives. The findings were fairly consistent with the results of Butler (1990) with regard to frequency of modal verbs and similar to the results by Crismore and Farnsworth (1990) in that professional science writing and popular science writing were not very different in terms of writers' use of modal verbs, hedges and boosters.

Meanwhile, Hyland (1998) analyzed 56 research articles, one paper from each of seven leading journals in eight disciplines: mechanical engineering, electrical engineering, marketing, philosophy, sociology, applied linguistics, physics, and microbiology. The results indicated that hedges exceeded boosters by nearly three to one. The most frequent hedges were may, would and possible, whereas the most frequent boosters were will, show, and the fact that. Modal lexical verbs, such as suggest, indicate, assume, and seem were also frequently used as hedges. There were substantial differences in the disciplinary results. That is, over $70 \%$ of all hedges occurred in philosophy, marketing, applied linguistics, and sociology, and they were over twice as frequent as in electrical engineering, mechanical engineering, and physics. Furthermore, Hyland explained that writers in humanities/social sciences relied on a personal projection, while scientists and engineers showed their evaluation impersonally, constructing a context in which their claims appeared to arise from the research itself.

In sum, comparing hedges with boosters, hedges are more extensively used in academic articles, and they are densely located in the discussion section. This reflects the importance of the need for claims to be presented provisionally rather than assertively to gain ratification from powerful peer readers, especially in the discussion section. Moreover, Hyland (2012) explained that hedges are also used to invite the readers to get involved in open discussion about the nature of the propositions. The frequent use of hedges in discussion is a consequence of the fact that the authors don't seek to accomplish closure by reaching consensus on a particular issue but is more like a sign of the authors' willingness to continue conversation.

The studies (e.g., Crismore \& Farnsworth, 1990; Grabe \& Kaplan, 1997; Salager-Meyer, 1994) in hedges and boosters of L1 academic writing have compared the frequencies of hedges and boosters to find differences in the use of hedges and boosters. However, they didn't further analyze what sort of hedges associated with modality was used by reflecting on the nature of different disciplinary characteristics. Accordingly, the present study will look into the differences in the use of hedges more deeply by drawing on the different nature of eight different disciplines.

\section{METHOD}

The present study is inspired by the study by Hyland (1998). A corpus of published research articles provides the data for the present study. The text corpus consists of 56 research articles, one paper from each of seven leading journals in eight disciplines in the three study fields of cultural sciences, social sciences and natural sciences. The eight disciplines are linguistics and philosophy in the cultural sciences, marketing and sociology in the social sciences and physics, electrical engineering, mechanical engineering, and chemistry in the natural sciences. The articles were chosen at random from current issues and limited to ones written by native speakers of English. The articles were converted into an electronic corpus of 369,605 words and were searched for lexical expressions

Table 3. Hedges and boosters in the corpus of 56 academic articles

\begin{tabular}{lcc}
\hline Category & Hedges & Boosters \\
\hline Adjectives & $1247(3.37)$ & $900(2.44)$ \\
Adverbs & $1669(4.52)$ & $650(1.76)$ \\
Auxiliaries & $1663(4.50)$ & $451(1.22)$ \\
Nouns & $1669(4.52)$ & $1207(3.27)$ \\
Verbs & $2595(7.02)$ & $1394(3.77)$ \\
Totals & $8843(23.93)$ & $4602(12.45)$ \\
Items per 1000 words & 23.93 & 12.45 \\
\hline
\end{tabular}


Table 4. Most frequent hedges and boosters in the corpus of 56 academic articles

\begin{tabular}{llll}
\hline Hedges & & Boosters & \\
\hline Device & Frequency & Device & Frequency \\
May & $666(1.80)$ & Will & $359(0.97)$ \\
Would & $423(1.14)$ & Truth & $291(0.79)$ \\
Suggest & $342(0.93)$ & Evidence & $254(0.69)$ \\
Could & $279(0.76)$ & Show & $209(0.57)$ \\
Consider & $249(0.67)$ & Determine & $167(0.45)$ \\
Possible & $235(0.64)$ & Finding & $159(0.43)$ \\
Indicate & $231(0.63)$ & Fact & $155(0.42)$ \\
Theory & $228(0.62)$ & Demonstration & $105(0.28)$ \\
Might & $181(0.49)$ & Reveal & $99(0.27)$ \\
Rather & $171(0.46)$ & Always & $91(0.25)$ \\
\hline
\end{tabular}

Table 5. Disciplinary differences in hedges and boosters

\begin{tabular}{lll}
\hline Category & Hedges & Boosters \\
\hline Linguistics & $1181(23.46)$ & $599(11.9)$ \\
Philosophy & $1860(40.40)$ & $1326(28.8)$ \\
Marketing & $1681(25.98)$ & $753(11.6)$ \\
Sociology & $1382(25.58)$ & $573(10.6)$ \\
Physics & $868(21.20)$ & $397(9.7)$ \\
Electrical Engineering & $362(13.79)$ & $236(9.0)$ \\
Mechanical Engineering & $949(17.62)$ & $473(8.8)$ \\
Chemistry & $560(16.78)$ & $245(7.3)$ \\
Totals & 8843 & 4602 \\
\hline
\end{tabular}

Note. The figures in the parentheses show the numbers per 1000 words.

of hedging and boosting using AntConc 3.4.3 (Anthony, 2014). All cases of hedges and boosters were checked by a native speaker of English ${ }^{2}$ to ensure that they expressed doubt or certainty.

\section{RESULTS AND DISCUSSION \\ Quantitative results}

The normality assumption was verified through SPSS, which did not show a violation of the normality assumption in the data shown in Tables 3 and 4. The results of the $t$-test in Table 3 show that hedges exceeded boosters by nearly 2 to $1, t(4)=4.56, p=.010<.05$, which reveals that tentative claims were made more than conclusive ones.

Table 4 shows the most frequently occurring hedges and boosters in the corpus with may and would accounting for almost $12 \%$ of the hedging devices and will and truth $14 \%$ of the boosting devices in the corpus.

Table 5 shows disciplinary differences in hedges and boosters, with philosophy containing almost 5.3 times as many hedges and boosters as electrical engineering. Hedges exceeded boosters in all disciplines, $t(7)=9.49, p=.000<.05$, and approximately $70 \%$ of all hedges and boosters occurred in humanities and social sciences, with philosophy papers evidencing considerable use of hedges and boosters. Hyland (2012) mentioned that philosophers spell out their arguments from personal reflection rather than empirical evidence in more discursive detail with a greater use of hedges and the inclusive we, working harder to establish solidarity and taking great care to create an understanding with their readers. The natural science papers were underrepresented in the number of hedges and boosters, although the discrepancies were not so large. Leech (1999) described that the most definite and assured statement is an unmodified assertion and any modification creates doubt and undermines the strength of the claim. The natural sciences deal with numerical data, which is more likely to generate a more precise picture of their findings, and it may seem that the authors in the natural sciences consider that using hedges and boosters distorts the fact from the empirical evidence.

\section{Hedges and boosters in academic articles}

Hedges and boosters are interactional strategies for increasing or reducing the force of propositional statements. The concept of hedges and boosters includes the modification of words or phrases within a proposition and also the modification of one's commitment to the propositional content. Hedges and boosters alter the state of affairs by indicating some markedness with respect to class membership of a particular item within a proposition or by changing the relationship between the propositional content and the writer by inserting the writer's uncertainty or certainty. For instance, somewhat (e.g., That's somewhat what I thinking about) and precisely (e.g., That's precisely what I am thinking about) 
Takimoto, A corpus-based analysis of hedges and boosters...

Table 6. Disciplinary differences in the use of approximative adverbs, approximately and nearly

\begin{tabular}{llll}
\hline & Humanities & Social Sciences & Natural Sciences \\
\hline approximately & $4(0.04)$ & $3(0.03)$ & $72(0.5)$ \\
nearly & $2(0.02)$ & $11(0.09)$ & $20(0.13)$ \\
\hline
\end{tabular}

Note. The figures in the parentheses show the numbers per 1000 words.

within a proposition will affect the class membership of a particular item, while I suppose (e.g., I suppose she will come), and I know (e.g., I know she will come) will alter the writer's commitment to the propositional content. As hedges and boosters are concerned with the writer's personal attitudes toward the propositional content, hedges and boosters belong to the semantic domain of modality. With modality, it is very clear that certain lexical and grammatical environments constitute a metaphorical realization of modality. The lexical metaphor is viewed as a variation in the use of words or a variation in their meaning. In this aspect, a lexeme with a certain literal meaning can have metaphorical meanings. According to conceptual metaphor theory by Lakoff \& Johnson (1999; Grady, 1999), humans use their understanding of the physical world as a framework for representing more abstract concepts.

With respect to class membership of a particular item within a proposition, although there were not many differences in the types of hedges and boosters used among humanities, social sciences, and natural sciences, a greater use of approximative adverbs, approximately and nearly, was found in natural science papers. In natural sciences, empirical evidence is usually provided with numerical data and writers need to take great care to highlight more precise information:

(1) The barotropic kinetic energy should be approximately five times larger than the total baroclinic energy at each wavenumber. (Journal of Computational Physics, 271)

The two species are present in nearly equal quantities, although the peaks were not sufficiently resolved to integrate or quantify. (Bioorganic \& Medicinal Chemistry, 22)

In these examples, the purpose of using hedges like approximative adverbs was not to dilute their certainty but, instead, to present a real picture of how far their measurement varies from standard disciplinary norms and to create shared understandings with the readers.

In the following examples, the writers use lexical verbs as hedges to carry the writers' uncertainty and as boosters to show their certainty in the truth of their propositions.

(2) Our results suggest bidirectional mapping, from source to target domain, as well as from target to the source domain. (Cognitive Linguistics, 23)

Our studies indicate that a parodic ad can undermine consumers' attitudes toward these entities. (Journal of Consumer Psychology, 24)

We expect that this linear response is quite general. (Nuclear Physics A, 927)

Together these cases show that the letter of the Intuitive Thought is wrong. (Erkenntnis, 79)

We know that comparatively differentiated and complex social contexts encourage increasing interaction, while simultaneously devaluing traditional and affective action orientations. (Annual Review of Sociology, 39)

We find that the PSD of the residual phase fluctuations is totally negligible, as compared to the mixer contribution. (IEEE Transactions on Microwave Theory and Techniques, 62)

The above examples draw attention to the contents of propositions and the writers' doubt or confidence about the propositions as well as to the readers' doubt or confidence. Hyland (2012) explained that the writers adjust the level of their commitment depending on the nature of the accredited facts or interpretations about the propositions and also on the anticipated effect the writers' commitments are likely to have on the readers' reactions. These considerations play very important roles in writing academic articles because they contribute to negotiating with the readers, persuading them that the writers' claims are valid, and helping the writers to obtain acceptance for their work in their disciplines. For instance, hedges are used not only as a strategy to get writers' provisional statements accepted by the readers but also as the writers' invitation to the readers to get involved in an open discussion about the nature of the propositions and the writers' views. The following sample provides an example of this:

(3) In response to the first question, it seems plausible to suppose that fundamental truths can only ground other truths. (Inquiry, 57)

Employing markers of evidential modality with inclusive pronouns (e.g., we) or indefinite pronouns (e.g., one) enables the writers to produce more interpersonal signals to the readers, which may allow the writers to share contexts with the readers and draw on their assumed belief specific to a particular field of study (Hyland, 1998):

(4) One might think that pressing this slippery slope argument is straightforward.

(Journal of Philosophy of Education, 47)

One could argue that, while this measure captures the positive and most obvious idea of mestizaje (mixture), mestizaje is a more complex belief structure that includes, and hides, the idea of black and indigenous assimilation or disappearance. (American Journal of Sociology, 118)

If, without in any way disturbing a system, we can predict with certainty the value of a physical quantity, then there exists an element of physical reality corresponding to this physical quantity. (Annals of Physics, 338)

On the other hand, boosters are used not only as a strategy to persuade the readers of the writers' confident assertion but also as a strategy to restrict the negotiating space available to the readers. The following sentence gives an example of this: 
(5) The fact that a belief was caused in this way rather than some other can play a crucial role in a special kind of coherentist justification. (Mind, 122)

Boosters such as of course, obvious(ly), clear(ly), well-known and so on also function to indicate a mutual understanding between the writers and the readers based on shared community membership, and they assist the writers in leading the readers to the same reasonable inferences or conclusions (Hyland, 1998). By including the readers in this way, the argument about the propositions and the solidarity with the readers that leads them to the same inferences or conclusions are strengthened:

(6) Of course, I am not merely hearing the noises you make, or merely seeing the movements you perform. (Philosophy, 89)

These findings clearly contradict our hypothesis 1 , in which we predicted widespread denial of inequality's structural basis, including discrimination. (American Journal of Sociology, 118)

Geometric instability is not always obvious when grinding because lobing builds up slowly. (International

\section{Journal of Machine Tools \& Manufacture, 82)}

This section examined hedges and boosters from the standpoint of lexical metaphor, and the view can be complemented by grammatical metaphor, as shown in the next section.

\section{Subjectivity and objectivity}

The starting point of the grammatical metaphor is a particular meaning, and it extends the different ways in which this meaning can be expressed or realized. From this point of view, the grammatical metaphor is defined as a variation in the expression of meanings. Halliday \& Matthiessen (2014) explained that the semantic domain of modality is extended through interpersonal grammatical metaphor to include explicit indications of subjective and objective orientation. The tendency of interpersonal metaphor is to upgrade the domain of grammatical realization. For example, the metaphorical realization is a clause that projects (e.g., I think ...) or embeds (e.g., it is probable ...) the clause to which a modal value is allotted, whereas the congruent

Table 7. Subjective/objective dimension of grammatical metaphor

\begin{tabular}{llll}
\hline & Subjective & Objective \\
\hline Explicit & Hedge & I suppose that ... & It is likely that ... \\
& Booster & I know that $\ldots$ & It is certain that $\ldots$ \\
\hline
\end{tabular}

realization of modality is a group serving within the clause. They subcategorized two layers of modality (modalization and modulation) into four complex dimensions of meaning with respect to the writer's modal responsibility (how much explicit responsibility the writer takes for his/her attitudes along the axes of subjective-objective and explicit-implicit). Both the subjective explicit orientation (e.g., I am certain that ....) and the objective explicit orientation (e.g., It is certain that ....) are based on grammatical metaphor because expressions of modality are extended from vocabulary to clauses by adding a projecting clause. With the examples of the subjective explicit orientation and the objective explicit orientation, the writer is explicitly stating the source of the conviction, but they are different along the subjective/objective dimensions. In the subjective explicit orientation case, the writer suggests that he/she alone knows the evidence and draws a conclusion from it, assuming strictly personal responsibility for the epistemic judgment (epistemic modality), whereas in the objective explicit orientation case, the writer indicates that the evidence is accessible to a larger group of people who share the conclusion based on it, assuming a shared responsibility for its judgment (evidential modality).

Although there were no significant differences among disciplines from a numerical point of view, the writers in humanities and social sciences were more likely to emphasize subjectivity, whereas the ones in natural sciences were inclined to stress objectivity when they modified statements. This indicates that the authors in humanities and social sciences were more likely to assume personal responsibility for their epistemic judgment by a more frequent use of cognitive verbs such as think and were more willing to be involved in their judgment by using personal attribution.

Table 8. Disciplinary differences in the use of cognitive verb, think

\begin{tabular}{llll}
\hline & Humanities & $\begin{array}{l}\text { Social } \\
\text { Sciences }\end{array}$ & $\begin{array}{l}\text { Natural } \\
\text { Sciences }\end{array}$ \\
\hline Think & $128(1.3)$ & $82(0.7)$ & $5(0.03)$ \\
\hline
\end{tabular}

Note. The figures in the parentheses show the numbers per 1000 words.

This result coincides with those reported by Hyland $(1998,2002)$ with more cases in humanities and social sciences in which the writers chose to link themselves with their ideas more explicitly to avoid a personal intervention:

(7) I think I probably follow that format most of the time. (TESOL Quarterly, 48)

I think that it is right, and assume it is for the purposes of this paper. (Erkenntnis, 79)

I think he would have been quite pleased with the idea that at some point I would be doing this now. (The Sociological Review, 61)

Hyland (2012) suggested that this tendency reflects the contents of textbooks by Day (2006) and Swales \& Feak (2004) that scientists are encouraged to make their own voice clear by the use of personal attribution in science papers.

By contrast, the writers in the natural sciences tended to opt for assuming a shared responsibility for their judgments with people who were accessible to the evidence and shared 
the conclusion based on it. By emphasizing author invisibility with a more frequent use of discourseoriented verbs such as indicate, which carry fewer subjective connotations than cognitive verbs, the authors were able to produce more accurate depictions of the real discovery and allow the facts to speak for themselves more clearly.

Table 9. Disciplinary differences in the use of discourse-oriented verb, indicate

\begin{tabular}{llll}
\hline & Humanities & $\begin{array}{l}\text { Social } \\
\text { Sciences }\end{array}$ & $\begin{array}{l}\text { Natural } \\
\text { Sciences }\end{array}$ \\
\hline Indicate & $14(0.15)$ & $17(0.14)$ & $122(0.8)$ \\
\hline
\end{tabular}

Note. The figures in the parentheses show the numbers per 1000 words.

The objectivity intention can be more easily realized by resorting to impersonal strategies such as faceless subjects, abstract subjects, agentless passives and dummy it, and this effect is more reinforced by the use of an embedded clause with an anticipatory or dummy it in place of a human agent as the subject (Hyland, 1998):

(8) It is believed that these higher order correlations capture the intrinsic flow contributions and reduce the effects of fluctuations. (Nuclear Physics A, 927)

It does not appear that the assumption of thermodynamic equilibrium used in developing them is valid for extreme reacting flows. (Proceeding of the Combustion Institute, 34)

LC-MS/MS analysis confirmed that the modification was localized to either Cys60 or Asp61, both of which could act as nucleophiles to displace the bromine. (Bioorganic \& Medicinal Chemistry, 22)

These studies together indicate that the effect of cations on LPS structure and aggregate formation is an important factor that should be considered when studying the manifestation of endotoxic shock. (Biophysical Journal, 106)

The above discussion suggests that the lengthy time historically required to develop advanced environmental technologies tends to diminish the probability of commercial success, as more mature technologies gain initial market share. (Progress in Energy and Combustion, 38)

It was evident that one needed to introduce lowpass filters to ensure that the laser energy does not overwhelm the TR signal. (Microelectronics Journal, 45)

It is likely that stronger Bragg grating effects will be seen than for current open 'plasmonic photonic crystal' structures due

Table 10. Disciplinary differences in personal and impersonal strategies

\begin{tabular}{|c|c|c|c|c|}
\hline & & Humanities & Social Sciences & Natural Sciences \\
\hline \multirow[t]{3}{*}{ Subjective Explicit } & Hedges & $64(0.7)$ & $34(0.3)$ & $20(0.1)$ \\
\hline & Boosters & $37(0.4)$ & $27(0.2)$ & $24(0.2)$ \\
\hline & Totals & $101(1.0)$ & $61(0.5)$ & $44(0.3)$ \\
\hline \multirow{3}{*}{$\begin{array}{l}\text { Objective Explicit } \\
\text { (with dummy it) }\end{array}$} & Hedges & $57(0.6)$ & $19(0.2)$ & $57(0.4)$ \\
\hline & Boosters & $29(0.3)$ & $5(0.04)$ & $43(0.3)$ \\
\hline & Totals & $86(0.9)$ & $24(0.2)$ & $100(0.6)$ \\
\hline \multirow{3}{*}{$\begin{array}{l}\text { Faceless subjects (e.g., The } \\
\text { result indicates ...) , A bstract } \\
\text { subject (e.g., To learn sh ows } \\
\text {..), Agentless passives (e.g., } \\
\text { Many of the troops may have } \\
\text { been injured ...) }\end{array}$} & Hedges & $98(1.0)$ & $159(1.3)$ & $187(1.2)$ \\
\hline & Boosters & $74(0.8)$ & $113(1.0)$ & $180(1.2)$ \\
\hline & Totals & $172(1.8)$ & $272(2.3)$ & $367(2.4)$ \\
\hline
\end{tabular}

to the better confinement of the optical field close to the metal surface. (Journal of Lightwave Technology, 15)

Table 10 shows disciplinary differences in personal and impersonal strategies. Hyland (2012) indicated that the textbooks by Gong \& Dragga (2001) and Lester (2004) advise scientists to avoid personal interventions and to comment impersonally on the validity of their propositions. Hyland (1998) further argued that writers use boosters such as establish and show to emphasize the strength and suggest the efficacy of the relationship between data and claims:

(9) This shows that the heat flux is a difficult statistic to correctly predict in a coarse - resolution simulation at weak supercriticality. (Journal of Computational Physics, 271)

This established that collector heating resulted from direct radiation heating rather than greenhouse effect within the chamber. (Microsystem Technologies, 19)
Adjectives, adverbs, verbs and nouns as hedges associated with modality

As the previous sections show, hedges outnumber boosters in academic articles and play important roles in contributing to negotiating with the readers and persuading them of the validity of the writers' claims and helping the writers to obtain acceptance for their work in their disciplines. Accordingly, the present section further examines the use of hedges in line with the categories associated with modality. However, modal auxiliaries were excluded from further investigation because they express one type of epistemic meaning (possibility/ probability). Although there were no significant differences among disciplines, the present study looks into the nature of different disciplinary characteristics from a numerical point of view. 


\begin{abstract}
Adjectives and adverbs
Possibility/probability. A variety of adjectives and adverbs are closely linked to modality (Perkins, 1983), and this category indicates tentative epistemic modality. With respect to adjectives, 46 different adjectives were identified, amounting to a total of 996 instances of hedging. Possible $(n=235)$, likely $(n=165)$, and potential $(n=148)$ were the top three in terms of frequency in all disciplines. The relative incidence of hedges of this type was the highest in humanities and the lowest in natural sciences. Regarding adverbs, 17 different nouns of this type were detected as hedges with a total of 281 occurrences. The items most commonly employed as hedges were perhaps $(n=72)$ and potentially $(n=44)$ and they were the top two in all disciplines. As with adjectives, humanities was more heavily hedged with this type of adverb and natural sciences was less heavily hedged.
\end{abstract}

Indefinite frequency. The second category, indefinite frequency, is used for hedging purposes due to its inherent indefiniteness. Regarding adjectives, there were seven different adjectives identified, with a total of 216 instances of hedging. General $(n=130)$ and common $(n=$ 52) had the highest frequency in all disciplines. The relative incidence of hedges of this type was similar across the three academic fields. Concerning adverbs, 13 different adverbs of this type were detected as hedges with a total of 523 occurrences. The items most commonly employed as hedges were often $(n=161)$, generally $(n=72)$ and typically $(n=123)$ and they were the top two in all disciplines. Humanities and social sciences were more heavily hedged with this type of adverbs than natural sciences.

Indefinite degree. The third category, indefinite degree, indicates epistemic qualifications, and they make the writers' statements less absolute. Regarding adjectives, four different adjectives were identified, amounting to a total of 87 instances of hedging. Most $(n=38)$ and reasonable $(n=21)$ were the two most frequent in all disciplines. The incidence of hedges of this type was

Table 11. Adjectives as hedges associated with modality

\begin{tabular}{llll}
\hline & Humanities & Social Sciences & Natural Sciences \\
\hline Possibility/ Probability & $394(4.1) 13.0 \%$ & $267(2.2) 8.7 \%$ & $280(1.8) 10.2 \%$ \\
Indefinite frequency & $63(0.7) 2.1 \%$ & $72(0.6) 2.4 \%$ & $78(0.5) 2.8 \%$ \\
Indefinite degree & $29(0.3) 1.0 \%$ & $21(0.2) 0.7 \%$ & $32(0.2) 1.2 \%$ \\
Approximation & 0 & 0 & $8(0.05) 0.3 \%$ \\
\hline
\end{tabular}

Note. The figures in the parentheses show the numbers per 1000 words and percentage of all hedges in each of the three study fields.

Table 12. Adverbs as hedges associated with modality

\begin{tabular}{llll}
\hline & Humanities & Social Sciences & Natural Sciences \\
\hline Possibility/ Probability & $115(1.2) 3.8 \%$ & $94(0.8) 3.1 \%$ & $95(0.6) 3.5 \%$ \\
Indefinite frequency & $160(1.7) 5.3 \%$ & $220(1.9) 7.2 \%$ & $172(1.1) 6.3 \%$ \\
Indefinite degree & $187(1.9) 6.1 \%$ & $225(1.9) 7.3 \%$ & $242(1.6) 8.8 \%$ \\
Approximation & $35(0.4) 1.2 \%$ & $42(0.4) 1.4 \%$ & $83(0.5) 3.0 \%$ \\
\hline
\end{tabular}

Note. The figures in the parentheses show the numbers per 1000 words and percentage of all hedges in each of the three study fields.

similar in all disciplines. With respect to adverbs, 20 different adverbs of this type were detected as hedges with a total of 610 occurrences. The items most commonly employed as hedges were rather $(n=171)$ and relatively $(n=89)$ and they were the top two in all disciplines. Like with adjectives, there was not a great difference in the incidence of hedges of this type across the disciplines.

Approximation. The last category, approximation, is commonly used to manipulate precision in quantification, and adverbs of this type are also used to hedge the effect of the predicate, reducing the force of the verb. With respect to adjectives, there were only two different adjectives with a total of nine occurrences, which belong to this category. They were approximate ( $n$ $=6)$ and rough $(n=3)$. The relative incidence of hedges of this type was observed only in natural sciences. Regarding adverbs, six different adverbs of this type were detected as hedges with a total of 182 occurrences. The items most commonly employed as hedges were approximately $(n=79)$ and almost $(n=40)$, and they were the top two in all disciplines. There was not a great difference in the incidence of hedges of this type across the disciplines. Verbs and nouns

Non-factive claim. Non-factive devices are useful in constructing claims by other researchers or in tentatively asserting the authors' ideas. Regarding full verbs, there were 11 different full verbs with a total of 924 occurrences that belong to this category. Suggest ( $n=$ $342)$, indicate $(n=231)$, and predict $(n=126)$ were the top three in terms of frequency in all disciplines. The relative incidence of hedges of this type was the highest in social sciences, and it includes more variety of the verbs employed. Concerning nouns, nine different nouns of this type were detected as hedges with a total of 286 occurrences. The items most commonly employed as 
hedges were proposition $(n=126)$, prediction $(n=65)$, and implication $(n=47)$ and they were the top three in all disciplines. Unlike with full verbs, humanities was more heavily hedged with this type of nouns and included more variety of this type.

Tentative cognition. The second category of verbs and nouns is the tentative cognition category, which is related to the mental processes of the writers or speakers. Regarding full verbs, 38 different full verbs were identified, amounting to a total of 1263 instances of hedging. Consider $(n=249)$, assume $(n=165)$, and expect $(n=160)$ were the top three in terms of frequency in all disciplines. The relative incidence of hedges of this type was that humanities and social sciences were more heavily hedged than natural sciences. Concerning nouns, 31 different nouns of this type were detected as hedges with a total of 923 occurrences. The items most commonly employed as hedges were theory $(n=228)$ and

Table 13. Nouns as hedges associated with modality

\begin{tabular}{llll}
\hline & Humanities & Social Sciences & Natural Sciences \\
\hline Non-factive claim & $267(2.8) 8.8 \%$ & $102(0.9) 3.3 \%$ & $106(0.7) 3.9 \%$ \\
Tentative cognition & $269(2.8) 8.8 \%$ & $370(3.1) 12.1 \%$ & $147(0.95) 5.4 \%$ \\
Tentative likelihood & $200(2.1) 6.6 \%$ & $80(0.67) 2.6 \%$ & $123(0.80) 4.5 \%$ \\
\hline
\end{tabular}

Note. The figures in the parentheses show the numbers per 1000 words and percentage of all hedges in each of the three study fields.

Table 14. Verbs as hedges associated with modality

\begin{tabular}{llll}
\hline & Humanities & Social Sciences & Natural Sciences \\
\hline Non-factive claim & $219(2.3) 7.2 \%$ & $332(2.8) 10.8 \%$ & $373(2.4) 13.6 \%$ \\
Tentative cognition & $444(4.6) 14.6 \%$ & $414(3.5) 13.5 \%$ & $413(2.7) 15.1 \%$ \\
Tentative likelihood & $157(1.6) 5.2 \%$ & $120(1.0) 3.9 \%$ & $110(0.7) 4.0 \%$ \\
\hline
\end{tabular}

Note. The figures in the parentheses show the numbers per 1000 words and percentage of all hedges in each of the three study fields.

hypothesis $(n=152)$, and they were the top two in all disciplines. Like full verbs, humanities and social sciences were more heavily hedged with this type of noun than natural sciences.

Tentative likelihood. The third category is similar to the previous two categories discussed so far as it refers to tentativeness concerning either the ideas put forth by the writers or those expressed in the sources referred to. Regarding full verbs, there were five different full verbs with a total of 387 occurrences that belonged to this category. Appear $(n=160)$, seem $(n=141)$, and tend $(n=$ $80)$ were the top three in terms of frequency in all disciplines. The relative incidence of hedges of this type was the highest in humanities. With respect to nouns, 16 different nouns of this type were detected as hedges with a total of 376 occurrences. The items most commonly employed as hedges were feasibility $(n=79)$, possibility $(n=73)$, and trend $(n=55)$, and they were the top three in all disciplines. Like full verbs, the discipline of humanities was more heavily hedged with this type of noun.

\section{CONCLUSION}

The present study conducted an analysis of research articles from eight academic disciplines to see the frequencies and functions of hedges and boosters. The quantitative results showed that hedges exceeded boosters by nearly 2 to 1 , and $70 \%$ of all hedges and boosters were found in humanities and social sciences, with philosophy articles evidencing a significant use of hedges and boosters. The natural science papers were underrepresented in the number of hedges and boosters. Using hedges and boosters in a text might be to some extent seen as the discourse choice of individual researchers influenced by individual personality, writing style preferences, and experiences in the field. However, in academic writing, the choices writers make seem to be constrained by the discourse norms and rhetorical styles of each discipline and reflect the nature of different disciplinary characteristics. The humanities and social sciences are basically more interpretative and less abstract, which requires more hedges and boosters and opts for subjectivity, whereas natural sciences are typically more fact-oriented and more impersonal, which is accompanied by fewer hedges and boosters and opts for objectivity. This is evidenced by the further analysis of hedges, showing that the relative incidence of hedges of the possibility/ probability category in adjectives and adverbs was the highest in humanities and the lowest in natural sciences. Moreover, the relative incidence of hedges of the tentative cognition category in nouns and verbs was the highest in humanities and social sciences and the lowest in natural sciences. Whatever the case may be, regardless of discipline, hedges and boosters work together to balance subjective evaluation and objective information with anticipated reactions from readers and aim to persuade readers to accept their claims. Nevertheless, no research is conclusive, leaving some room for uncertainty, and research cannot be reported with the same confidence of shared beliefs across disciplines. Thus, research has to be expressed with more hedges than boosters.

The present study found frequencies and functions of hedges and boosters in the academic articles of the 
humanities, social sciences, and natural sciences by native speakers of English, but it is not clear whether the tendency that the present study found can be applicable to articles from other disciplines or those by non-native speakers of English. Accordingly, for future research, it would be interesting to look into how hedges and boosters are dealt with in other disciplines and by nonnative speakers of English. In this way, we will be able to grasp differences and similarities in the use of hedges and boosters by native and non-native speakers of English and provide learners of English with guiding principles regarding the use of hedges and boosters in academic articles.

\section{Acknowledgments}

This work was supported by Grant-in-Aid for Scientific Research 26370632.

I am heartily thankful to my supervisor, Toshio Ohori, for his skillful guidance and invaluable comments during the development of this study.

\section{NOTES}

1. In this case, just as in the situation in which one knows that John belongs to a community of ninety of which thirty are unmarried, the epistemic judgment is based on some kind of evidence (perceived evidence, hearsay evidence, inferences from other knowledge, etc.).

2. A native speaker of English is defined as a person who speaks English as their first language and has not learned it as a foreign language.

\section{REFERENCES}

Anthony, L. (2014). AntConc 3.4.3: Waseda University. Butler, C. (1990). Qualifications in science: modal meanings in scientific texts. In W. Nash (ed.), The writing scholar: Studies in academic discourse (pp. 137-170). Newbury Park, CA: Sage.

Chafe, W. (1986). Evidentiality in English conversation and academic writing. In W. Chafe \& J. Nichols (eds.), Evidentiality: The coding of epistemology in language (pp. 261-272). Norwood, N.J. : Ablex.

Crismore, A., \& Farnsworth, R. (1990). Metadiscourse in popular and professional science discourse. In W. Nash (ed.), The writing scholar: Studies in academic discourse (pp. 118-136). Newbury Park, C.A.: Sage.

Day, R. (2006). How to write and publish a scientific paper. Phoenix, AZ: Oryx Press.

Fetzer, A. (2010). Hedges in context: Form and function of sort of and kind of. In G. Kaltenböck, W. Mihatsch, \& S. Schneider (eds.), New approaches to hedging (pp.15-34). UK: Emerald Group Publishing Ltd.

Fraser, B. (2010). Pragmatic competence: The case of hedging. In G. Kaltenböck, W. Mihatsch, \& S. Schneider (eds.), New approaches to hedging (pp.15-34). UK: Emerald Group Publishing Ltd.
Gong, G. \& Dragga, S. (2001). A writer's repertoire. New York: Longman.

Grabe, W., \& Kaplan, R. (1997). On the writing of science and the science of writing: Hedging in science text and elsewhere. In R. Markkanen \& H. Schröder (eds.), Hedging and discourse: Approaches to the analysis of a Pragmatic phenomenon in academic texts (pp. 3-18). Berlin: Walter de Gruyter.

Grady, J. (1999). A typology of motivation for conceptual metaphor: Correlation vs. resemblance. In R. Gibbs, \& G. Steen (eds.), Metaphor in cognitive linguistics (pp. 79-100). Amsterdam: John Benjamins.

Halliday, M., \& Matthiessen, C. (2014). Halliday's introduction to functional grammar. London:Routledge.

Holmes, J. (1995). Women, men and politeness. London: Longman.

Hyland, K. (1998). Boosting, hedging and the negotiation of academic knowledge. Texts, 18(3), pp. 349-382.

Hyland, K. (2002). Authority and invisibility: authorial identity in academic writing. Journal of Pragmatics, 34(8), pp. 1091-1112.

Hyland, K. (2012). Disciplinary identities: Individuality and community in academic discourse. Cambridge: Cambridge University Press.

Lakoff, G. (1972). Hedges: A study of in meaning criteria and the logic of fuzzy concepts. Chicago Linguistic Society Papers, 8, pp. 183-228.

Lakoff, G., \& Johnson, M. (1999). Philosophy in the flesh. New York: Basic Books.

Leech, G. (1999). Semantics: the study of meaning. London: Penguin.

Lester, J. (2004). Writing research papers. New York: Harper Collins.

Markkanen, R., \& Schröder, H. (1997). Hedging: A challenge for pragmatics and discourse analysis. In R. Markkanen \& H. Schröder (eds.), Hedging and discourse: Approaches to the analysis of a Pragmatic phenomenon in academic texts (pp. 318). Berlin: Walter de Gruyter.

Nuyts, J. (2006). Modality: Overview and linguistic issues. In W. Frawley (ed.), The expression of modality (pp. 1-26). Berlin: Mouton.

Palmer, F. (2007). Mood and Modality. Cambridge: Cambridge University press.

Perkins, M. (1983). Modal expressions in English. London: Frances Pinter.

Salager-Meyer, F. (1994). Hedges and textual communicative function in medical English written discource. English for Special Purposes, 13, pp. 149-170.

Swales, J. \& Feak, C. (2004). Academic Writing for Graduate Students, Second Edition: Essential Tasks and Skills (Michigan Series in English for Academic \& Professional Purposes). Michigan: University of Michigan Press. 


\section{Appendix 1: Journal Corpus}

English in today's research world: a writing guide. Ann Arbor, MI: University of Michigan Press.

Varttala, T. (2001). Hedging in scientifically oriented discourse exploring variation

according to discipline and intended audience. Unpublished doctoral dissertation.

University of Tampere.

\section{Linguistics}

Applied Linguistics (2014), Volume 35 Issue 1

The Modern Language Journal (2014), Volume 98 Issue 2

Studies in Second Language Acquisition (2014), Volume 36 Issue 2

TESOL Quarterly (2014), Volume 48 Issue 1

Journal of Pragmatics (2013), Volume 28 Issue 4

Metaphor and Symbol (2013), Volume28 Issue 4

Cognitive Linguistics (2012), Volume 23 Issue 1

\section{Philosophy}

Mind(2013), Volume 122 Issue 485

Journal of Philosophy (2013), Volume 47 Issue 4

International Journal for Philosophy of Religion (2014), Volume 75 Issue 3

The Philosophical Quarterly (2013), Volume 63 Issue 252

Philosophy (2014), Volume 89, Issue 1

Erkenntnis (2014), Volume 79, Issue 1

Inquiry (2014), Volume 57 Issue 2

\section{Marketing}

International Journal of Management \& Marketing Research (2014), Volume 7 Issue 1

International Journal of Research in Marketing (2014), Volume 31 Issue 1

Journal of Business Research (2014), Volume 67 Issue 8

Journal of Advertising (2014), Volume 43 Issue 2

Journal of the Academy of Marketing Science (2014), Volume 42 Issue 3

Journal of Consumer Psychology (2014), Volume24 Issue 1

Psychology and Marketing (2014), Volume 31 Issue 6

\section{Sociology}

American Journal of Sociology (2013), Volume 118 Issue 6

The Sociological Review (2013), Volume 61 Issue 2

Annual Review of Sociology (2013), Volume 39

International Journal of Comparative Sociology (2013), Volume 54 Issue 4

Sociology (2014), Volume 48 Issue 2
International Sociology (2013), Volume 28 Issue 4

The British Journal of Sociology (2013), Volume 64 Issue2

Physics

Journal of Magnetism and Magnetic Materials (2014), Volume 363

Applied Physics (2014), Volume 114 Issue 4

Annals of Physics (2013), Volume 338

Journal of Computational Physics (2014), Volume 271

Nuclear Physics A (2014), Volume 927

Biophysical Journal (2014), Volume 106 Issue 11

Computer Physics Communication (2014), Volume 185 Issue 7

\section{Electrical Engineering}

Microelectronics Journal (2014), Volume 45 Issue 5

Microsystem Technologies (2013), Volume 9 Issue 7

IEEE Transactions on Microwave Theory and Techniques (2014), Volume 62 Issue 2

Solid State Electronics (2013), Volume 87

Analog Integrated Circuits \& Signal Processing (2014), Volume 78 Issue 3

Progress in Quantum Electronics (2013), Volume 37 Issue 6

Journal of Lightwave Technology(2013), Volume 15

\section{Mechanical Engineering}

Mechanism and Machine Theory (2014), Volume 78

Progress in Energy and Combustion (2012), Volume 38 Issue 5

International Journal of Mechanical Sciences (2013), Volume 77

International Journal of Plasticity (2014), Volume 60

Proceedings of the Combustion Institute (2013), Volume 34 Issue 2

International Journal of Heat and Mass Transfer (2014), Volume 74

International Journal of Machine Tools \& Manufacture (2014), Volume 82

\section{Chemistry}

Accounts of Chemical Research (2013), Volume 46 Issue 6

Journal of the American Chemical Society (2014), Volume 136 Issue 23

Chemistry of Materials (2014), Volume 26 Issue 11

Bioorganic \& Medicinal Chemistry (2014), Volume 22 Issue 13

Bioorganic Chemistry (2012), Volume 40

Biophysical Chemistry (2014), Volume 185

Computational and Theoretical Chemistry (2014), Volume 1033 